\title{
Malposition of Heart and Cardiac Apex
}

National Cancer Institute

\section{Source}

National Cancer Institute. Malposition of Heart and Cardiac Apex. NCI Thesaurus. Code C34804.

Any anatomical misplacement of the heart and cardiac apex such that the organ occupies an unusual location within the body. 